\title{
Development of a Survey Instrument to Explore the Characteristics of Australian Private Physiotherapy Practitioners' Interprofessional Interactions
}

Jack A. Seaton

James Cook University, jack.seaton@my.jcu.edu.au

Anne Jones

James Cook University, anne.jones@jcu.edu.au

Catherine L. Johnston

University of Newcastle, cath.johnston@newcastle.edu.au

Karen Francis

University of Tasmania, karen.francis@utas.edu.au

Follow this and additional works at: https://nsuworks.nova.edu/ijahsp

Part of the Physical Therapy Commons, and the Physiotherapy Commons

\section{Recommended Citation}

Seaton JA, Jones A, Johnston CL, Francis K. Development of a Survey Instrument to Explore the Characteristics of Australian Private Physiotherapy Practitioners' Interprofessional Interactions. The Internet Journal of Allied Health Sciences and Practice. 2020 Jan 01;18(4), Article 2.

This Manuscript is brought to you for free and open access by the College of Health Care Sciences at NSUWorks. It has been accepted for inclusion in Internet Journal of Allied Health Sciences and Practice by an authorized editor of NSUWorks. For more information, please contact nsuworks@nova.edu. 


\title{
Development of a Survey Instrument to Explore the Characteristics of Australian Private Physiotherapy Practitioners' Interprofessional Interactions
}

\begin{abstract}
Background: Interprofessional collaboration is a complex process defined by the relationships and interactions between health practitioners from diverse professional backgrounds. Although the benefits of a collaborative health workforce are widely acknowledged, it is currently poorly understood to what extent private physiotherapy practitioners engage in interprofessional collaboration as a part of their clinical practice, and whether they consider to be adequately trained in this area. Information regarding the frequency, modes of communication, and perceived level of satisfaction associated with private physiotherapy practitioners' interprofessional interactions is also limited. Purpose: The aim of this paper is to describe the development of a survey instrument that can be used to explore the characteristics of Australian private physiotherapy practitioners' interprofessional interactions. Methods: A multiphase process was used to develop the survey instrument. The research team conducted a literature search which resulted in the generation of 34 individual survey items. After the initial pool of survey items was developed, three experienced physiotherapists were invited to review the items. The draft survey instrument was then subject to online testing with private physiotherapy practitioners to evaluate the utility of the instrument. Results: All three physiotherapists invited to review the initial pool of survey items provided written feedback to the research team. Following revision, five private physiotherapy practitioners participated in pilot testing the survey instrument. Pilot testing revealed that approximately 10 minutes was required to complete the online survey. Conclusions: The final survey instrument has 29 questions in six sections with categorical, Likert and free text response options and can be used to explore the characteristics of Australian private physiotherapy practitioners' interprofessional interactions. Information obtained from future research projects utilising this survey may guide the development of effective interventions aimed at enhancing the nature and quality of clinical interactions between private physiotherapy practitioners and other health practitioners working in Australia.
\end{abstract}

\section{Author Bio(s)}

ack A. Seaton, BPhty (Hons), is a PhD Candidate in the College of Healthcare Sciences and Lecturer within the College of Public Health, Medical and Veterinary Sciences at James Cook University in Townsville, Australia. He is also a registered physiotherapist with the Australian Health Practitioner Regulation Agency (AHPRA).

Anne L. Jones, BSc (Phty), MPhty (Rural Remote Area Studies), PhD, is a Senior Lecturer and Head of the Physiotherapy discipline at James Cook University in Townsville, Australia.

Catherine L. Johnston, BAppSc (Phty), MAppSc (Cardiopulm Phty), PhD, is a Senior Lecturer and Clinical Education Manager/Physiotherapy Program Convenor at The University of Newcastle in Callaghan, Australia.

Karen L. Francis, BHealthSc (Nsg), MHIth Sc (PHC), MEd, PhD, is a Professor and Head of the Nursing discipline at The University of Tasmania in Launceston, Australia.

\section{Acknowledgements}

This research is supported by an Australian Government Research Training Program Scholarship (RTPS). No specific funding or material support of any kind was received for the work described in this article. 


\title{
1UAHSP
}

\section{The Internet Joutnal of Allied Health Sciences and Practice}

Dedicated to allied health professional practice and education

Vol. 18 No. 4 ISSN 1540-580X

\section{Development of a Survey Instrument to Explore to Characteristics of Australia Private Physiotherapy Practitioners' Interprofessional Interactions}

\author{
Jack A. Seaton ${ }^{1}$ \\ Anne Jones ${ }^{1}$ \\ Catherine L. Johnston ${ }^{2}$ \\ Karen Francis ${ }^{3}$ \\ 1. James Cook University \\ 2. University of Newcastle \\ 3. University of Tasmania
}

Australia

\begin{abstract}
Background: Interprofessional collaboration is a complex process defined by the relationships and interactions between health practitioners from diverse professional backgrounds. Although the benefits of a collaborative health workforce are widely acknowledged, it is currently poorly understood to what extent private physiotherapy practitioners engage in interprofessional collaboration as a part of their clinical practice, and whether they consider to be adequately trained in this area. Information regarding the frequency, modes of communication, and perceived level of satisfaction associated with private physiotherapy practitioners' interprofessional interactions is also limited. Purpose: The aim of this paper is to describe the development of a survey instrument that can be used to explore the characteristics of Australian private physiotherapy practitioners' interprofessional interactions. Methods: A multiphase process was used to develop the survey instrument. The research team conducted a literature search which resulted in the generation of 34 individual survey items. After the initial pool of survey items was developed, three experienced physiotherapists were invited to review the items. The draft survey instrument was then subject to online testing with private physiotherapy practitioners to evaluate the utility of the instrument. Results: All three physiotherapists invited to review the initial pool of survey items provided written feedback to the research team. Following revision, five private physiotherapy practitioners participated in pilot testing the survey instrument. Pilot testing revealed that approximately 10 minutes was required to complete the online survey. Conclusions: The final survey instrument has 29 questions in six sections with categorical, Likert and free text response options and can be used to explore the characteristics of Australian private physiotherapy practitioners' interprofessional interactions. Information obtained from future research projects utilising this survey may guide the development of effective interventions aimed at enhancing the nature and quality of clinical interactions between private physiotherapy practitioners and other health practitioners working in Australia.
\end{abstract}

Keywords: Australia, interprofessional collaboration, physical therapy, primary health care, private practice, questionnaire. 


\section{INTRODUCTION}

Physiotherapy represents one of the largest allied health professions in Australia, accounting for more than 30,000 qualified practitioners. ${ }^{1}$ Physiotherapists are responsible for the provision of services to people across the lifespan in the management of various health issues. ${ }^{2}$ In Australia, physiotherapists are employed in both the public and private sectors and in metropolitan, regional, rural, and remote locations. ${ }^{3}$ Most physiotherapists work primarily as clinicians and practise in a range of settings including hospitals, private practice, community and rehabilitation centres, residential aged care, and sporting organisations. ${ }^{3}$ The remainder of physiotherapists assume roles in areas such as management, research, and tertiary education..$^{3-4}$

There has been a significant rise in the proportion of physiotherapists working in private practice in recent decades. Physiotherapy private practices are described as professional businesses or for-profit organisations that are not funded through government departments. ${ }^{5}$ Private physiotherapy services are predominately funded by the individual in a fee-forservice environment, with rebates or fee supports available through various insurance schemes. ${ }^{6}$ Health workforce data indicates that less than one third of physiotherapists worked in the private sector in 1975, while it was reported that seventy per cent of Australian physiotherapists were employed in private practice in 2018. ${ }^{1,4}$ This changing demographic of primary workplace may be indicative of the increasing demand for access to physiotherapy in the community. ${ }^{7}$

Physiotherapists, including those employed in private practice, are encouraged to collaborate with health practitioners from various professional backgrounds to enhance the quality of patient care. ${ }^{8}$ This process of interprofessional collaboration refers to the interactions and relationships between and among health practitioners from different professions. ${ }^{9}$ The features of successful collaborative practice include sharing a holistic view on patient care, working together to achieve common goals and mutual respect, trust, and understanding. ${ }^{10}$ Interprofessional collaboration facilitates the provision of costeffective health care and contributes to superior patient outcomes and enhanced patient and practitioner satisfaction. ${ }^{11}$ Additionally, a collaborative health workforce has been shown to be more responsive and efficient and is linked to improved staff retention in rural and remote areas. ${ }^{11-12}$

Interprofessional collaboration is best observed when formal team structures exist and opportunity for frequent, informal communication is high. ${ }^{13}$ However, occasions for physiotherapists to interact with health practitioners from other professions are potentially limited in physiotherapy private practice by the dominant service delivery model which is commonly a small monodisciplinary clinic. ${ }^{3}$ According to a recent study, private physiotherapy practitioners in Canada perceived interprofessional collaboration to be indirect and mostly limited to referrals to and from other health practitioners..$^{14}$ As such, the nature and quality of private physiotherapy practitioners' interprofessional interactions may not align with often-found definitions of interprofessional collaboration that typically involve formal meetings to discuss specific patient cases. ${ }^{15}$ In regional and rural areas, geographic isolation, workforce shortages and service centralisation may also present as additional barriers to effective interprofessional collaboration. ${ }^{16}$

The experiences of health practitioners regarding interprofessional collaboration in primary health care has attracted previous attention in the literature; however, most of this research concerns the professions of medicine and nursing. . $3,17^{-17}$ Despite the documented benefits of interprofessional collaboration, it remains a poorly understood process in some primary health care settings, such as physiotherapy private practice. It is unclear to what extent private physiotherapy practitioners in Australia engage in interprofessional collaboration as a part of their clinical practice, and if they perceive to be adequately trained in this area. Furthermore, there is little information regarding private physiotherapy practitioners' clinical interactions with health practitioners from different professions, specifically the frequency, modes of communication and perceived level of satisfaction associated with these interactions.

In order to guide the development of effective interventions aimed at promoting and improving interprofessional collaboration in physiotherapy private practice, it is necessary to gain a current understanding of private physiotherapy practitioners' interactions and relationships with health practitioners from various professional backgrounds. At present, no published survey instrument exists to obtain information regarding interprofessional collaborative practice from the perspective of health practitioners, including physiotherapists, working in clinical settings that do not necessarily adhere to formal team-based processes. The aim of this study was to develop a survey instrument that can be used to explore the characteristics of Australian private physiotherapy practitioners' interprofessional interactions.

\section{METHODS}

Development of the survey instrument involved a multiphase process (Figure 1): (i) literature search; (ii) survey item development; (iii) review and revision of survey items; and (iv) pilot testing with a sample of physiotherapists employed in 
private practice. Ethical approval was received from the James Cook University Human Research Ethics Committee (Reference no. H7639).

\begin{tabular}{|c|}
\hline Literature Search \\
\hline Literature search to determine if an acceptable tool already exists to measure the structure of interest \\
\hline Survey Item Development \\
\hline Individual survey items ( $\mathrm{n}=34$ ) were developed by the research team informed by the project aims and literature \\
\hline search \\
\hline Review and Revision of Survey Items \\
\hline Experienced physiotherapists $(\mathrm{n}=3)$ reviewed the survey items and provided written feedback to the research team \\
\hline Pilot Testing \\
\hline Private physiotherapy practitioners ( $\mathrm{n}=5$ ) participated in pilot testing the online survey to evaluate the utility of the \\
instrument
\end{tabular}

Figure 1. Phases of Survey Instrument Development

\section{Literature Search and Survey Item Development}

The multiprofessional research team, with professional backgrounds in physiotherapy and nursing, conducted an extensive literature search to identify existing surveys or questionnaires that could be used as a frame of reference for constructing a new survey instrument. Most of the measures of interprofessional interactions identified focused on the professions of medicine and nursing, and many tools were designed for data collection within specific health care settings. ${ }^{18-21}$ The search found only one published instrument used to collect data pertaining to interprofessional interactions specifically for the physiotherapy profession; however, the content lacked relevance to the physiotherapy private practice workforce in Australia as a result of differences in service delivery. ${ }^{22}$

From the literature search, and further informed by the project aims and an integrative literature review conducted by the research team, a list was created containing factors that were previously cited as important when examining interprofessional interactions in other clinical environments. ${ }^{23-25}$ The list was then adapted to account for the proportion of private physiotherapy practitioners in Australia who may not participate in formal multidisciplinary teamwork but could still have frequent interactions with health practitioners from other professions. This process resulted in the generation of 34 individual survey items that the research team deemed adequate to represent the construct of interest.

\section{Review and Revision of Initial Survey Items}

After the initial pool of survey items was developed, three experienced physiotherapists were selected to review the items. The physiotherapists were known to the research team and were chosen due to their past clinical experience of greater than ten years in physiotherapy private practice. The selected physiotherapists reviewed the individual survey items to ensure they were accurate, free of item construction flaws (vulnerabilities that may make survey items subject to misinterpretation), and grammatically correct. They were also asked to identify missing elements which may influence interprofessional interactions for private physiotherapy practitioners, discern whether any items were redundant, and to nominate items for deletion. The physiotherapists' responses were reviewed, and consensus of all members of the research team was required prior to excluding or amending any individual survey item.

\section{Survey Instrument Pilot Testing}

The draft survey instrument was subject to online testing to evaluate the utility of the instrument. The objective of this evaluation was to ascertain whether the survey instrument functioned as intended and could be completed in a time efficient manner. A sample of physiotherapists $(n=37)$ employed in physiotherapy private practice facilities were invited to participate in pilot testing the online survey instrument. Purposeful sampling was used to select physiotherapy private practice facilities from one region of New South Wales, Australia. The contact details of physiotherapists were obtained via the publicly accessible 'Find a Physio' search tool (https://choose.physio/findaphysio, accessed 24 July 2019). The search tool is an index of Australian physiotherapy private practice facilities maintained by the Australian Physiotherapy Association. One physiotherapist at each private practice facility was sent an invitation to participate in pilot testing of the anonymous survey instrument. Each email invitation contained a participant information statement and a hyperlink to the 
survey instrument, hosted online using Qualtrics ${ }^{\mathrm{TM}}$. A reminder email was sent to all participants two and four weeks following the initial invite. Completion and submission of the online survey constituted informed participant consent.

\section{RESULTS}

\section{Review and Revision of Initial Survey Items}

All three experienced physiotherapists invited to review the initial pool of survey items provided written feedback to the research team. The recommendations provided mostly related to addition and deletion of individual survey items, and minor suggestions were given to improve the clarity of the wording. One physiotherapist questioned the appropriateness of the term "collaboration" in survey items asking participants about their day-to-day clinical interactions without reference to the relationships that they share with health practitioners from other professions, and how these are formed and maintained over time. Instead, use of the term "interprofessional interactions" was suggested as an alternative and changes were made to the relevant survey items accordingly. Another participant recommended revising the sequence of individual survey items to ensure the survey structure was logical.

Based on the physiotherapists' feedback, two additional survey items were developed, and seven individual survey items were removed. One survey item was added to elicit further information about the clientele private physiotherapy practitioners provide services to, while another question was introduced to ask participants to rate their perceived level of satisfaction regarding their previous interprofessional interactions. A collective decision was made by the research team to delete survey items that the physiotherapists deemed to be redundant and not adequately assessing the construct of interest.

The revised draft survey instrument consisted of 29 questions in six sections: participant characteristics, workplace information, previous training regarding interprofessional collaboration, clinical interactions with other health practitioners, opinions towards interprofessional collaboration, and general comments. Survey item responses included a combination of closed categorical questions, Likert scale items, and free text response options.

\section{Survey Instrument Pilot Testing}

Five physiotherapists participated in pilot testing the survey instrument, with an overall response rate of $14 \%$. The mean age of participants was 51 years (standard deviation 11 years) and all participants reported that they had more than 10 years of clinical experience working as a physiotherapist in private practice. Every participant indicated that they were the principal physiotherapist at their respective private practice facilities. All participants stated that they had previously been employed as a physiotherapist in other clinical settings, mainly public hospitals.

Pilot testing indicated that approximately 10 minutes was required to complete the survey, demonstrating that the survey length was appropriate (range 6 minutes, 39 seconds -12 minutes, 25 seconds). Review of participant responses revealed that the survey instrument was functioning as intended in its online format with respect to access via the survey hyperlink, data format rules and "skip logic" functions. Across all questions requiring a closed categorical response, only one question yielded missing data (question 12, asking participants to indicate how often they would treat people across a range of physiotherapy clinical areas within their private practice caseload). Written responses were provided by the majority of participants $(n=4,80 \%)$ for each question requiring a free text response.

\section{DISCUSSION}

To the authors' knowledge, this is the first published survey instrument developed to allow for the collection of data regarding the characteristics of interprofessional interactions involving private physiotherapy practitioners in Australia. The survey instrument was developed with input from a multiprofessional research team based on gaps in current literature and utilising published recommendations for survey instrument development. ${ }^{26}$ The project occurred in several well-defined stages including a literature search, survey item development, review and revision of survey items and pilot testing with a sample of private physiotherapy practitioners prior to the formulation of a final survey instrument. Individual survey items and corresponding response options were extensively reviewed and revised to minimise measurement error, with careful consideration given to the overall survey length and structure to enhance utility. The final survey instrument, consisting of 29 questions in six sections, is user-friendly, easily comprehendible, and of appropriate length and content for use with private physiotherapy practitioners in Australia (Appendix 1).

\section{Implications}

Although the survey instrument has been developed for dissemination amongst private physiotherapy practitioners in Australia, globally, interprofessional collaboration is an expected standard of care for all health practitioners. ${ }^{8-9}$ Therefore, the results of this research may be of interest to private physiotherapy practitioners internationally, as well as health 
practitioners from different professions who work in similar clinical settings with similar clientele. This survey instrument could be adapted in the future to explore the characteristics of interprofessional interactions in various geographical locations and involving health practitioners from diverse professional backgrounds. Collecting information regarding the characteristics of interprofessional interactions from different health professions across a range of geographical contexts would enable comparison of documented clinical interactions and may offer opportunities for scopes of practice to be clarified and roles and responsibilities to be asserted. Furthermore, this acquired knowledge could assist in the development of training strategies and practical recommendations to enhance the nature and quality of health practitioners' interprofessional interactions.

\section{Limitations}

The main limitation of this study was that a small sample of private physiotherapy practitioners from only one Australian region were invited to pilot test the survey instrument. The physiotherapists involved in pilot testing the survey instrument had a range of clinical experience, were working in a variety of physiotherapy private practice settings and their characteristics (including gender, physiotherapy qualification, location and primary scope of practice) are comparable to publicly available data on the Australian physiotherapy workforce. ${ }^{3}$ Therefore, they would appear to be generally representative of private physiotherapy practitioners currently working in Australia. Given the small sample size, no statistical or cognitive pre-testing measures could be applied to the survey instrument to assess the validity or reliability of the tool. Despite this, the survey instrument was deemed to have adequate depth and detail to represent the construct of interest on review and appears suitable for use in a larger sample. An additional limitation of the study may be a response bias due to surveys only being completed by one physiotherapist at each private practice facility. However, many of the questions required factual answers rather than personal opinion; therefore, it is likely that responses among physiotherapists working at the same facility would generally be consistent.

\section{CONCLUSION}

The outcome of this study is the development of a survey instrument with input from a multiprofessional research team and following detailed review by a range of physiotherapists. The survey instrument can be used to explore the characteristics of Australian private physiotherapy practitioners' interprofessional interactions, including the frequency, modes of communication and level of satisfaction associated with such interactions. Information obtained from future research projects utilising this survey may guide the development of effective interventions aimed at enhancing the nature and quality of clinical interactions between private physiotherapy practitioners and other health professionals in Australia.

\section{REFERENCES}

1. Australian Health Practitioner Regulation Agency. Annual Report 2017/2018.

https://www.ahpra.gov.au/annualreport/2018/downloads. Accessed 14 September, 2019.

2. World Confederation for Physical Therapy. Policy Statement: Description of Physical Therapy.

https://www.wcpt.org/policy/ps-descriptionPT. Accessed 14 September, 2019.

3. Health Workforce Australia. Australia's Health Workforce Series - Physiotherapists in Focus.

https://www.health.gov.au/internet/main/publishing.nsf/Content/hwa-archived-publications. Accessed 16 July, 2019.

4. Anderson G, Ellis E, Williams V, Gates C. Profile of the physiotherapy profession in New South Wales (1975-2002).

Aust J Physiother. 2005;51(2):109-116. [PMID: 15924513]

5. Perreault K, Dionne C, Rossignol M, Poitras S, Morin D. Physiotherapy practice in the private sector: organizational characteristics and models. BMC Health Serv Res. 2014;14(1):362. [PMID: 25168160]

6 . Adams R, Jones A, Lefmann S, Sheppard L. Towards understanding the availability of physiotherapy services in rural Australia. Rural Remote Health. 2016;16(2):3686. [PMID: 27289169]

7. Pretorius A, Karunaratne N, Fehring S. Australian physiotherapy workforce at a glance: a narrative review. Aust Health Rev. 2016;40(4): 438-442. [PMID: 26536297]

8. D'Amour D, Goulet L, Labadie J, Martín-Rodriguez L, Pineault R. A model and typology of collaboration between professionals in healthcare organizations. BMC Health Serv Res. 2008;8(1):188. [PMID: 18803881]

9. World Health Organization. Framework for action on interprofessional education and collaborative practice. https://www.who.int/hrh/resources/framework_action/en/. Accessed 14 September, 2019.

10. D'Amour D, Ferrada-Videla M, San Martin Rodriguez L, Beaulieu M. The conceptual basis for interprofessional collaboration: core concepts and theoretical frameworks. J Interprof Care. 2005;19(Suppl 1):116-131. [PMID: 16096150] 
11. Reeves S, Pelone F, Harrison R, Goldman J, Zwarenstein M. Interprofessional collaboration to improve professional practice and healthcare outcomes. Cochrane Database Syst Rev. 2017;6:CD000072. [PMID: 28639262]

12. Senate Community Affairs References Committee. The Factors Affecting the Supply of Health Services and Medical Professionals in Rural Areas. https://trove.nla.gov.au/work/170930674?selectedversion=NBD50001439. Accessed 14 September, 2019.

13. Morgan S, Pullon S, McKinlay E. Observation of interprofessional collaborative practice in primary care teams: an integrative literature review. Int J Nurs Stud. 2015;52(7): 1217-1230. [PMID: 25862411]

14. Perreault K, Dionne CE, Rossignol M, Morin D. Interprofessional practices of physiotherapists working with adults with low back pain in Québec's private sector: results of a qualitative study. BMC Musculoskelet Disord. 2014;15(1):160. [PMID: 24884757]

15. Reeves S, Lewin S, Espin S, Zwarenstein M. Interprofessional teamwork for health and social care. Hoboken, New Jersey: Blackwell-Wiley; 2010.

16. Australian Institute of Health and Welfare. Rural, regional and remote health: indicators of health status and determinants of health. https://www.aihw.gov.au/reports/rural-remote-australians/rural-regional-remote-healthindicators/contents/table-of-contents. Accessed 18 July, 2019.

17. McInnes S, Peters K, Bonney A, Halcomb E. An integrative review of facilitators and barriers influencing collaboration and teamwork between general practitioners and nurses working in general practice. J Adv Nurs. 2015;71(9):1973-1985. [PMID: 25731727]

18. Weiss S, Davis H. Validity and reliability of the collaborative practice scales. Nurs Res. 1985; 34(5):299-305. [PMID: 3850490]

19. Shortell S, Rousseau D, Gillies R, Devers M, Simons T. Organizational assessment in intensive care units: construct development, reliability and validity of the ICU nurse physician questionnaire. Med Care. 1991;29(8): 709-726. [PMID: 1875739]

20. Parker Oliver D, Wittenberg-Lyles E, Day M. Measuring interdisciplinary perceptions of collaboration on hospice teams. Am J Hosp Palliat Care. 2007;24(1):49-53. [PMID: 17347505]

21. Careau E, Brière N, Houle N, Dumont S, Vincent C, Swaine B. Interprofessional collaboration: development of a tool to enhance knowledge translation. Disabil Rehabil. 2015;37(4):372-378. [PMID: 24828392]

22. Perreault K, Dionne CE, Rossignol M, Morin D. Validation of a new tool to measure physiotherapists' interprofessional practices. J Allied Health. 2016;45(1):14-19. [PMID: 26937877]

23. Seaton J, Jones A, Johnston C, Francis F. Allied health professionals' perceptions of interprofessional collaboration in primary health care: an integrative review. J Interprof Care. Forthcoming 2020.

24. Reeves S, Rice K, Conn LG, Miller K-L, Kenaszchuk C, Zwarenstein M. Interprofessional interaction, negotiation and non-negotiation on general internal medicine wards. J Interprof Care. 2009;23(6):633-645. [PMID: 19842957]

25. Goldman J, Reeves S, Wu R, Silver I, MacMillan K, Kitto S. Medical residents and interprofessional interactions in discharge: an ethnographic exploration of factors that affect negotiation. J Gen Intern Med. 2015;30(10):1454-1460.

[PMID: 25869018]

26. Tsang S, Royse CF, Terkawi AS. Guidelines for developing, translating, and validating a questionnaire in perioperative and pain medicine. Saudi J Anaesth. 2017;11(Suppl 1): S80-S89. [PMID: 28616007]

C The Internet Journal of Allied Health Sciences and Practice, 2020 
APPENDIX

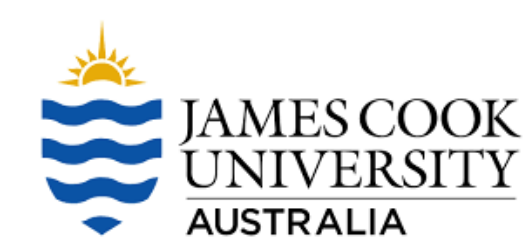

\section{EXPLORATION OF THE CHARACTERISTICS OF AUSTRALIAN PRIVATE PHYSIOTHERAPY PRACTITIONERS' INTERPROFESSIONAL INTERACTIONS}

\section{Section 1: Information about you and your physiotherapy qualification}

1. What is your gender? (Select one)

$\square$ Male

$\square$ Female

$\square$ Other

2. What is your age in years?

For the following questions, the term 'entry-level' refers to your primary physiotherapy qualification (e.g. Bachelor of Physiotherapy). 'Entry-level' does not include your post-graduate qualifications (e.g. PhD, MPH). Please note that a threeyear Masters degree (extended) allows the title of 'Doctor of Physiotherapy'.

3. Which of the following describes the entry-level physiotherapy training program you completed? (Select one)
Diploma
Bachelor degree
$\square$ Bachelor (Honours) degree
$\square$ Masters degree
$\square$ Masters degree (extended)
Other, please specify:

4. In what year did you complete your entry-level physiotherapy qualification?

5. Where did you complete your entry-level physiotherapy qualification? (Select one)

$\square$ Australia

$\square$ Overseas, please specify the country below:

6. How many years have you worked as a physiotherapist in a clinical role (excluding breaks of one year or greater)?

(Select one)

$\square$ Approximately 1 year

$\square$ Approximately 2 to 5 years

$\square$ Approximately 6 to 10 years

$\square$ Approximately 11 to 20 years

$\square$ Greater than 20 years

7. How many years have you worked as a physiotherapist in private practice (excluding breaks of one year or greater)?

(Select one)

$\square$ Approximately 1 year

$\square$ Approximately 2 to 5 years

$\square$ Approximately 6 to 10 years

$\square$ Approximately 11 to 20 years

C The Internet Journal of Allied Health Sciences and Practice, 2020 
$\square$ Greater than 20 years

8. Have you previously been employed as a physiotherapist in any of the following clinical settings? (Select all that apply)

$\square$ Public hospital

Private hospital

Community care

Residential aged care

Sporting organisation

Other, please specify:

\section{Section 2: Information about your workplace and the clientele you treat}

For the following questions, your 'private practice facility' refers to the workplace in which you spend most of your time during a typical working week.

9. Are you the principal physiotherapist at your private practice facility? (Select one)

$\square$ Yes

$\square$ No

10. What is the postcode of the town or city in which your private practice facility is located?

11. Within your private practice caseload, approximately how often would you treat people in each of the following age groups? (Select one for each category)

Rating of frequency of presentation

\begin{tabular}{lcccc}
\cline { 2 - 3 } Age: & Never & Rarely & Sometimes & Often \\
\hline 0-2 years & $\square$ & $\square$ & $\square$ & $\square$ \\
3-6 years & $\square$ & $\square$ & $\square$ & $\square$ \\
7-12 years & $\square$ & $\square$ & $\square$ & $\square$ \\
13-18 years & $\square$ & $\square$ & $\square$ & $\square$ \\
19-30 years & $\square$ & $\square$ & $\square$ & $\square$ \\
31-40 years & $\square$ & $\square$ & $\square$ & $\square$ \\
41-50 years & $\square$ & $\square$ & $\square$ & $\square$ \\
51-64 years & $\square$ & $\square$ & $\square$ & $\square$ \\
65-84 years & $\square$ & $\square$ & $\square$ & $\square$ \\
85 years and over & $\square$ & $\square$ & $\square$ & $\square$ \\
\hline
\end{tabular}

12. Within your private practice caseload, approximately how often would you treat people in each of the following physiotherapy clinical areas? (Select one for each category)

Rating of frequency of presentation

\begin{tabular}{lcccc}
\cline { 2 - 4 } Area: & Never & Rarely & Sometimes & Often \\
\hline Cardiorespiratory & $\square$ & $\square$ & $\square$ & $\square$
\end{tabular}

(C) The Internet Journal of Allied Health Sciences and Practice, 2020 
General rehabilitation

Musculoskeletal

Neurological

Occupational rehabilitation

Orthopaedics/trauma

Sports

Vestibular rehabilitation

Women's health

13. Within your private practice caseload, approximately how often would you treat people in each of the following stages of condition? (Select one for each category)

\section{Rating of frequency of presentation}

\begin{tabular}{lcccc}
\cline { 2 - 4 } Stage: & Never & Rarely & Sometimes & Often \\
\hline Acute (0-3 months) & $\square$ & $\square$ & $\square$ & $\square$ \\
Sub-acute (3-6 months) & $\square$ & $\square$ & $\square$ & $\square$ \\
Chronic (> 6 months) & $\square$ & $\square$ & $\square$ & $\square$ \\
\hline
\end{tabular}

For the following questions, a 'monodisciplinary' practice refers to a facility only employing one professional group (e.g. physiotherapists); a 'multidisciplinary' practice is one that incorporates health practitioners from two or more professional groups (e.g. physiotherapy and occupational therapy); and 'co-location' refers to health services that are located in the same physical space (e.g. office, building, campus), though not necessarily fully integrated with one another.

14. Which of the following best describes your private practice facility? (Select one)

$\square$ Monodisciplinary (Proceed to Q. 16)

$\square$ Multidisciplinary

15. Please indicate whether health practitioners from the following professions are employed by your private practice

(Select all that apply)

$\square$ Chiropractic

$\square$ Exercise physiology

$\square$ Massage therapy

$\square$ Medicine (general practitioner)

$\square$ Medicine (medical specialist, e.g. orthopaedic surgeon)

$\square$ Nursing

$\square$ Nutrition and dietetics

$\square$ Occupational therapy

$\square$ Osteopathy

Pharmacy

$\square$ Podiatry

$\square$ Psychology

$\square$ Speech pathology

$\square$ Other health profession, please specify: 
16. Is your private practice facility co-located with another health service? (Select one)

$\square$ Yes

$\square$ No (Proceed to Q. 18)

17. Please indicate which of the following health services are co-located with your private practice facility (Select all that apply)

$\square$ General practice clinic

$\square$ Orthopaedic surgery clinic

$\square$ Other surgery/specialty medical service, please specify:

$\square$ Pharmacy clinic

$\square$ Private hospital

Public hospital

Radiology clinic

Residential aged care facility

Other health service, please specify:

\section{Section 3: Information about your training relating to interprofessional collaboration}

For the remaining sections, the term 'interprofessional collaboration' refers to occasions when members from two or more health professions work together to solve problems or provide services.

18. Did you receive any training and/or information as a part of your entry-level physiotherapy program related to interprofessional collaboration? (Select one)
$\square$ Yes
$\square$ No (Proceed to Q. 20)
Unsure (Proceed to Q. 20)

19. In what form was the training and/or information related to interprofessional collaboration delivered? (Select all that apply)

$\square$ Clinical placement

E-learning / online platform (e.g. discussion boards)

$\square$ Lecture and / or seminar

$\square$ Practical / tutorial

$\square$ Simulation-based learning environment

$\square$ Other, please specify:

Unsure

20. Have you participated in any additional training programs specifically related to interprofessional collaboration since receiving your entry-level qualification? (Select one)

$\square$ Yes, please specify:

$\square$ No

21. Do you think you require more training related to interprofessional collaboration? (Select one)

$\square$ Yes

No

\section{Section 4: Information about your interprofessional interactions}

22. On average, how often would you interact with a health practitioner from another profession as a part of your private practice caseload? (Select one)

$\square$ Daily

$\square$ More than once a week

$\square$ Once a week

Less than once a week

(C) The Internet Journal of Allied Health Sciences and Practice, 2020 
23. As a physiotherapist working in private practice, which of the following means of communication do you use to interact with health practitioners from other professions? (Select all that apply)

$\square$ Email

$\square$ Face-to-face planned meeting

$\square$ Face-to-face unplanned meeting (e.g. corridor discussion)

$\square$ Joint evaluation or intervention

$\square$ Letter or form sent by fax or mail

$\square$ Letter or form sent through your patient

$\square$ Telephone

$\square$ Verbally transmitted message through your patient

$\square$ Videoconference (e.g. Skype)

$\square$ Other, please specify:

24. As a physiotherapist working in private practice, how would you rate your frequency of interaction with health practitioners from each of the following professions? (Select one for each profession)

Rating of frequency of interaction

\begin{tabular}{lcccc} 
& Never & Rarely & Sometimes & Often \\
Profession: & $\square$ & $\square$ & $\square$ & $\square$ \\
Chiropractic & $\square$ & $\square$ & $\square$ & $\square$ \\
Exercise physiology & $\square$ & $\square$ & $\square$ & $\square$ \\
Massage therapy & $\square$ & $\square$ & $\square$ & $\square$ \\
Medicine (general practitioner) & $\square$ & $\square$ & $\square$ & $\square$ \\
Medicine (medical specialist) & $\square$ & $\square$ & $\square$ & $\square$ \\
Nursing & $\square$ & $\square$ & $\square$ & $\square$ \\
Nutrition and dietetics & $\square$ & $\square$ & $\square$ & $\square$ \\
Occupational therapy & $\square$ & $\square$ & $\square$ & $\square$ \\
Osteopathy & $\square$ & $\square$ & $\square$ & $\square$ \\
Pharmacy & $\square$ & $\square$ & $\square$ \\
Podiatry & $\square$ & $\square$ & $\square$ \\
Psychology & $\square$ & $\square$ & $\square$ \\
Speech pathology & $\square$ & $\square$ & $\square$ \\
\hline
\end{tabular}

25. As a physiotherapist working in private practice, how would you rate your level of satisfaction regarding your previous interactions with health practitioners from other professions? (Select one)

$\square$ Very satisfied

$\square$ Moderately satisfied

$\square$ Slightly satisfied

$\square$ Not at all satisfied

$\square$ Not applicable 


\section{Section 5: Your opinions regarding interprofessional collaboration}

26. As a physiotherapist working in private practice, do you think that you need to collaborate with health practitioners from other professions to provide adequate care for the people you treat? (Select one)

$\square$ Yes

$\square$ No

27. As a physiotherapist working in private practice, what do you consider are the main benefits of interprofessional collaboration as it relates to your clinical practice?

28. As a physiotherapist working in private practice, what do you consider are the main challenges associated with interprofessional collaboration as it relates to your clinical practice?

\section{Section 6: General comments}

29. Do you have any additional comments relating to any aspect of interprofessional collaboration in physiotherapy private practice?

Thank you for completing this survey. 